\title{
Selection of Microorganisms for Biological Control of Silver Scurf (Helminthosporium solani) of Potato Tubers
}

\author{
M. K. Elson, Research Plant Pathologist, D. A. Schisler, Research Plant Pathologist, and R. J. Bothast, Research \\ Leader, Fermentation Biochemistry Research, USDA-ARS, National Center for Agricultural Utilization Research, \\ Peoria, IL 61604
}

\begin{abstract}
Elson, M. K., Schisler, D. A., and Bothast, R. J. 1997. Selection of microorganisms for biological control of silver scurf (Helminthosporium solani) of potato tubers. Plant Dis. 81:647652 .

Few management strategies exist for silver scurf, an important postharvest disease of potatoes. In this study, the microbiota of 47 agricultural soils and 7 tuber samples was screened for biological control agents of silver scurf. Soil or periderm samples were transferred to separate samples of $\gamma$ irradiation-sterilized field soil enriched with potato periderm. After incubation, the samples were assayed for biological suppressiveness to silver scurf using a whole-tuber/infested soil assay. Over 430 isolates of bacteria, yeasts, and actinomycetes were recovered from tubers and soil associated with the 12 most suppressive soil samples. Thirteen strains were selected for further study on three different strains of Helminthosporium solani, including one that was resistant to thiabendazole. Microbial strains that significantly inhibited $H$. solani $(P \leq 0.05)$ in at least one experiment were identified as Pseudomonas putida (PM1), Nocardia globerula (S244), and Xanthomonas campestris (P76). Colonization studies with rifampicin-resistant strains of putative biological control agents revealed that long-term colonization of the tuber surface was not necessary to reduce disease symptoms. Highly variable levels of conidiophore production prevented selection of the single most suppressive strain. Possible sources of variability in biological control are discussed, including physiological age of the tuber, tuber infection in the field, and uneven free moisture in the storage.
\end{abstract}

Silver scurf, caused by Helminthosporium solani Durieu \& Mont., is an important storage disease of potatoes (Solanum tuberosum L.) (3). It cost the potato industry $\$ 8.5$ million in Idaho alone during 1992 and 1993 (17). Symptoms of silver scurf are limited to the tuber periderm, so disease costs are associated with reduced quality caused by discoloration and sloughing of the skin, and moisture losses caused by rupture of periderm integrity. However, periderm rupture may increase susceptibility of the tubers to other storage diseases that require wounds in order to infect. Silver scurf has increased in importance recently because many strains of $H$. solani have developed resistance to thiabendazole (TBZ) $(8,14,21)$, a postharvest fungicide that has been traditionally applied to control Fusarium dry rot of potato tubers.

Other disease control strategies are needed because all commonly grown po-

Corresponding author: M. K. Elson

E-mail: melson@heartland.bradley.edu

Accepted for publication 7 March 1997

Publication no. D-1997-0424-04R

This article is in the public domain and not copyrightable. It may be freely reprinted with customary crediting of the source. The American Phytopathological Society, 1997. tato cultivars are susceptible to silver scurf $(15,20)$. Biological control of postharvest diseases of fruits and vegetables has proved feasible in numerous studies $(4,9,23)$, and research has led to several commercial biological control products (7). Several factors support the concept of developing biological control agents active against silver scurf of potato tubers. Adams et al. (1) found that soils with high total bacterial counts reduced silver scurf. Storage conditions favor biological control of silver scurf because $H$. solani multiplies during brief periods of free moisture in the potato storage (11). Putative biological control agents would benefit from these same periods of free moisture. Chun and Shetty (5) demonstrated that a strain of Pseudomonas corrugata could reduce silver scurf, but large-scale screening for microorganisms with enhanced biological activity against silver scurf has not been attempted.

The goal of this study was to conduct the first large-scale screening for silver scurf antagonists. The objectives were: (a) to select communities of microorganisms that protect potato tubers from $H$. solani infection, (b) to evaluate the biological control potential of the microorganisms isolated from the most suppressive of these communities, and (c) to evaluate the periderm colonization characteristics of selected antagonists that controlled silver scurf.

\section{MATERIALS AND METHODS}

Selection of soils suppressive to $\boldsymbol{H}$. solani. Soil and tuber samples were obtained from 47 sites throughout the United States and stored not more than 4 months at $4^{\circ} \mathrm{C}$ in loosely closed plastic bags. Individual samples of live soil (47 samples) or periderm with adhering live soil (7 samples) were added to $\gamma$ irradiation-sterilized (5 megarads minimum) silty loam field soil (Dakota silty loam; pH 6.8, 1:1 water:soil, $1.3 \%$ organic matter) containing heat-sterilized Russet Burbank potato periderm (5:93:2 wt/wt/wt, respectively). These mixtures produced samples that were chemically, physically, and nutritionally similar, but microbiologically different. Schisler and Slininger (19) found that periderm-enrichment improved the recovery of Fusarium-suppressive isolates. Soils were brought to approximately $10 \%$ moisture (dry weight basis) and incubated 1 week at $15^{\circ} \mathrm{C}$ with periodic shaking. The 47 soil samples were divided into 3 sets for testing.

Red Norland potato tubers were obtained from a commercial supplier of seed potatoes and stored in darkness at $8^{\circ} \mathrm{C}$. Several hours before use, tubers were brought to room temperature, gently washed with distilled water, sorted for lack of visible $H$. solani infection, and allowed to air-dry. The tubers were sorted by weight so that all treatments within a block would have similar surface areas.

$H$. solani strains were obtained from Loria (Cornell University, Ithaca, NY). $H$. solani SS2-2 was grown on Lima Bean Agar (Difco Laboratories, Detroit). $H$. solani inoculum was prepared by adding $10 \mathrm{ml}$ of phosphate buffer $(0.004 \%$ $\mathrm{KH}_{2} \mathrm{PO}_{4}, 0.019 \% \quad \mathrm{MgCl}_{2}, \mathrm{pH} 7.2$; AidPack USA, Gloucester, MA) to a 5-weekold culture and stirring with a sterile loop. Soil inoculum was prepared by adding 0.6 $\mathrm{g}$ of each periderm-enriched soil sample to $3 \mathrm{ml}$ of $\mathrm{H}$. solani conidial suspension $(2 \times$ $\left.10^{5} \mathrm{CFU} / \mathrm{ml}\right)$. This combined inoculum was sprayed onto four replicate tubers $(0.5$ $\mathrm{ml} /$ tuber). Controls consisted of uninoculated tubers and tubers inoculated with $H$. solani conidial suspension alone. The tubers were placed in plastic trays $(28 \times 53$ $\mathrm{cm}$ ) in a randomized block design. Trays were enclosed in large plastic bags containing moist towels, loosely closed, and incubated in darkness at $15^{\circ} \mathrm{C}$ for 6 weeks. This incubation temperature was chosen 
because it represents a compromise of early storage temperatures in commercial tuber storage houses and temperatures at which the disease will develop fairly rapidly.

After 6 weeks, tubers were rated for the presence of $H$. solani using a $25 \times$ dissecting microscope. Each tuber was divided into 16 microscope fields, which were rated plus or minus for the presence of $H$. solani conidiophores. The number of infected fields was converted to a percentage of the tuber surface area.

Isolation of microorganisms. In the event that some of the initially active strains of a suppressive soil would not be recoverable after 6 weeks, periderm samples were collected after 7 days from a fifth replicate. A 5-mm sterile cork borer and scalpel were used to cut periderm disks from five positions on each tuber. Periderm disks were suspended in $0.1 \%$ water agar and placed in an ultrasonic water bath (Branson 3200) for $2 \mathrm{~min}$ to dislodge the microorganisms. Serial dilutions were prepared in $\mathrm{PO}_{4}$ buffer and spread on selective media. Bacteria were selected on one-tenth strength tryptic soy broth agar (TSBA/10, Difco Laboratories) + cycloheximide $(0.05 \mathrm{~g} /$ liter $)$. Yeasts were selected on acidified YME agar (3.0 g yeast extract, $3.0 \mathrm{~g}$ malt extract, $5.0 \mathrm{~g}$ peptone [Type IV], 18 g Bacto Agar per liter) + chloramphenicol $(0.1 \mathrm{~g} /$ liter $)$, acidified with $1 \mathrm{M} \mathrm{HCl}$ to $\mathrm{pH} 3.7$ after autoclaving. Heat-tolerant bacteria were selected from dilutions that were heat-shocked for $3 \mathrm{~min}$ at $60^{\circ} \mathrm{C}$ and plated on TSBA $/ 10+$ cycloheximide. Plates were incubated for 4 days at $28^{\circ} \mathrm{C}$ and colonies were counted. These plates were stored at $4^{\circ} \mathrm{C}$ until the tubers were rated for silver scurf. Only those plates originating from soil determined to be the most suppressive to silver scurf were retained. Periderm samples from tubers with low silver scurf ratings after 6 weeks were also collected immediately after rating the tubers for silver scurf, and plated as described earlier. Because biologically based suppressiveness is the only plausible explanation for the treatments with low silver scurf ratings, microbial communities from these treatments were likely to contain individual strains that were suppressive to silver scurf. Strains that formed morphologically distinct colonies on the 7-day and 6-week plates were isolated on one-fifth strength tryptic soy agar (TSA/5, Difco Laboratories). These strains were streaked for purity and stored at $-80^{\circ} \mathrm{C}$ in $10 \%$ glycerol.

Efficacy of isolates against $\boldsymbol{H}$. solani SS2-2. A total of 268 individual microbial strains, isolated from periderm-enriched soils suppressive to $H$. solani, were sprayed onto single potato tubers to select the most suppressive strains. Tubers were sprayed with $0.5 \mathrm{ml} /$ tuber of $H$. solani conidial suspension $\left(1 \times 10^{5} \mathrm{CFU} / \mathrm{ml}\right)$, followed by $0.5 \mathrm{ml}$ of a microbial strain (OD 0.17 at $A_{620}$ ). Tubers were never sprayed to run-off. Inoculated tubers were placed in trays and incubated at $15^{\circ} \mathrm{C}$, as previously described. Thirty-nine strains that reduced conidiophore production to negligible levels were inoculated onto four replicate tubers to confirm their effectiveness for controlling silver scurf.

Membrane plates. A second isolation technique was attempted using cellophane membrane plates to determine if membrane plates could provide a more rapid screening method. Membrane disks $(8.5 \mathrm{~cm})$ were cut from cellophane sheets (Bio-Rad Laboratories, Richmond, CA) and autoclaved in 1 liter of distilled $\mathrm{H}_{2} \mathrm{O}$ for 20 min. Plates were prepared by placing a sterile membrane on the surface of a water agar plate (18 g/liter Bacto Agar, Difco Laboratories).

Suspensions of $H$. solani SS2-2 conidia and soil were prepared from each of the 54 periderm-enriched soil samples as described for tuber assays, and sprayed onto the membrane plates (approx. 0.25 $\mathrm{ml} / \mathrm{plate}$ ). The control plates were inoculated with $H$. solani conidial suspension alone. The membranes allowed growth of the microorganisms in a nutrient-limiting environment, but prevented penetration of fungi into the agar medium. The plates were incubated at $8^{\circ} \mathrm{C}$ for 14 days. Two replicate plates were prepared for each treatment.

After 14 days, germination of $100 \mathrm{H}$. solani conidia was counted using a $100 \times$ microscope. Treatments that suppressed germination of conidia were selected for isolation of individual microorganisms. Cells of mixed microbial populations were removed from each of the selected plates by scraping the membrane surface with a sterile, platinum wire loop. Cells were then suspended in $1 \mathrm{ml}$ of $\mathrm{PO}_{4}$ buffer. Suspensions were plated on selective media, as described previously. Morphologically distinct colonies were isolated into pure culture and stored at $-80^{\circ} \mathrm{C}$ in $10 \%$ glycerol. A total of 166 strains were inoculated onto single potato tubers, and 27 were selected for replicated assay, as described previously.

Efficacy of selected strains against additional strains of $\boldsymbol{H}$. solani. Seven strains from the whole tuber assays and six strains from the membrane plate assays were selected and tested against $H$. solani SS2-2 (TBZ-susceptible) and two additional strains of $H$. solani, HSND07 (TBZ-

Table 1. Replicated assays of putative antagonists selected from the single replicate assays

\begin{tabular}{|c|c|c|c|c|c|c|c|c|}
\hline \multicolumn{3}{|c|}{ Periderm assay } & \multicolumn{3}{|c|}{ Soil assay groups I and II } & \multicolumn{3}{|c|}{ Soil assay group III } \\
\hline Strain & $\begin{array}{c}\% \text { surface } \\
{\text { area } \text { affected }^{\mathrm{a}}}^{\text {ore }}\end{array}$ & $\begin{array}{c}\text { (\% of } \\
\text { control) }\end{array}$ & Strain & $\begin{array}{c}\% \text { surface } \\
\text { area affected }^{\mathrm{a}}\end{array}$ & $\begin{array}{c}\text { (\% of } \\
\text { control) }\end{array}$ & Strain & $\begin{array}{c}\% \text { surface } \\
\text { area affected }^{\mathrm{a}}\end{array}$ & $\begin{array}{l}\text { (\% of } \\
\text { control) }\end{array}$ \\
\hline$\overline{\mathrm{P} 1}$ & 70 & $(75)$ & S 1 & 94 & (111) & S306 & 93 & $(102)$ \\
\hline P 8 & $50 * *$ & (53) & S16 & 72 & (86) & S319 & 81 & (89) \\
\hline P11 & 86 & (92) & S18 & 71 & (83) & S323 & 81 & (89) \\
\hline P13 & 83 & (88) & S25 & 72 & (85) & S338 & 69 & (76) \\
\hline P17 & 87 & (93) & $\mathrm{S} 28$ & 55 & (65) & S339 & 85 & (93) \\
\hline P19 & 97 & (103) & S31 & 97 & $(115)$ & S340 & 73 & (81) \\
\hline $\mathrm{P} 20$ & 95 & (102) & S34 & 81 & (96) & S343 & 64 & (71) \\
\hline $\mathrm{P} 23$ & 85 & $(90)$ & S67 & 86 & (102) & $\mathrm{UC}^{\mathrm{b}}$ & 81 & (90) \\
\hline P27 & 83 & (88) & S205 & 97 & (115) & Control $(+\mathrm{HS})$ & 91 & \\
\hline $\mathrm{P} 30$ & 91 & (97) & S219 & 88 & (103) & & & \\
\hline P33 & 67 & (72) & S230 & 72 & $(86)$ & & & \\
\hline P37 & 85 & (90) & S235 & 67 & (80) & & & \\
\hline P58 & 78 & (83) & S242 & 73 & (87) & & & \\
\hline P71 & 75 & $(80)$ & S244 & 64 & (76) & & & \\
\hline P76 & $53 * *$ & (57) & S245 & $44^{*}$ & (52) & & & \\
\hline P77 & 93 & (99) & S271 & 71 & (83) & & & \\
\hline $\mathrm{UC}$ & $51 * *$ & $(55)$ & $\mathrm{UC}^{\mathrm{b}}$ & 75 & (89) & & & \\
\hline Control (+HS) & 94 & & Control (+HS) & 85 & & & & \\
\hline $\mathrm{LSD}_{0,05}$ & 37.3 & & & 42.6 & & & 31.2 & \\
\hline
\end{tabular}

${ }^{a}$ Means represent the average of 4 replicates. Values within a column are significantly different from the inoculated control $(+\mathrm{HS})$ at $P \leq 0.10(*), P \leq$ $0.05(* *)$, or $P \leq 0.01(* * *)$ based on Fisher's protected least significant difference (LSD).

${ }^{\mathrm{b}}$ Uninoculated control. 
resistant) and HSND25 (TBZ-susceptible). SS2-2 was grown as described earlier, while HSND07 and HSND25 were grown on CV8 medium $(175 \mathrm{ml}$ clarified V8 juice, $5.25 \mathrm{~g} \mathrm{CaCO}_{3}, 20 \mathrm{~g}$ Bacto Agar per liter). For each randomized block experiment, 5 replicate tubers were inoculated as described earlier. Each experiment was conducted twice.

Antagonist identification. Ten bacterial strains that limited disease development in at least one experiment were subjected to gas-chromatographic analysis of the phospholipid fatty acids according to the method of Sugimoto et al. (22), except that version 3.6 of the aerobic library was used. Strains were further identified with Biolog GN Microplates (version 3.5, Biolog, Inc., Hayward, CA). Traits of presumptively identified strains were compared with known specimens and published descriptions of genera and species (13). Biochemical and physiological tests of taxonomic utility were also run on these strains. The two yeast strains were identified by C. Kurtzman (NRRL Culture Collection, National Center for Agricultural Utilization Research [NCAUR], Peoria, IL). The Streptomyces strain was identified by D. Labeda (NRRL Culture Collection, NCAUR).

Tuber colonization by three strains. Spontaneous rifampicin-resistant strains of P8, P76, and PM1 (P8r, P76r, and PM1r, respectively) were selected by growing the isolates on TSA $/ 5$ amended with $50 \mu \mathrm{g} / \mathrm{ml}^{-1}$ of rifampicin (rif). Rifampicin-resistant strains possessed wild type growth rates in liquid culture and maintained antibiotic resistance when grown in the absence of rifampicin. Red Norland potato tubers were inoculated with $H$. solani SS2-2 conidial suspension and the rif-resistant antagonists, following the procedure described earlier. Five 5-mm periderm disks were cut from four replicate tubers at 0,2 , 4 , and 6 weeks. The disks were suspended in $1 \mathrm{ml}$ of $0.1 \%$ water agar and placed in an ultrasonic water bath, as before. Microdilutions were plated on TSA/5 containing $50 \mu \mathrm{g} / \mathrm{ml}^{-1}$ of rifampicin, and serial dilutions were spread-plated on TSA/5 and $1 / 5$ strength potato dextrose agar (PDA, Difco Laboratories) to obtain counts of total bacteria and fungi, respectively. After 6 weeks, the tubers were rated for the presence of conidiophores, as previously described. A $10 \times$ concentration $(\mathrm{OD}=1.7$ at $\left.A_{620}\right)$ of PM1 was included to determine if an increased cell concentration would increase biological control of $H$. solani. This experiment was conducted twice.

\section{RESULTS}

Isolation of microorganisms. Three microbial communities that were the most suppressive to the development of $\mathrm{H}$. solani conidiophores were selected from the seven treatments that consisted of periderm with adhering live soil. However, the sup- pressiveness of these communities was not significantly different from the control $(P$ $=0.21$ ). Conidiophores were visible on 9 to $53 \%$ of the surface area of the tubers treated with periderm-enriched soils. Microbial recovery from dilution of the periderm disks of these tubers ranged from $1.0 \times 10^{5}$ to $3.6 \times 10^{6} \mathrm{CFU} / \mathrm{cm}^{2}$ for bacteria, none detected to $9.75 \times 10^{4} \mathrm{CFU} / \mathrm{cm}^{2}$ for yeasts, and $2.5 \times 10^{3}$ to $8.4 \times 10^{4}$ $\mathrm{CFU} / \mathrm{cm}^{2}$ for heat-resistant bacteria. Thirty-seven strains were isolated from the 7-day samples and 31 from the 6-week samples. All were tested in single replication assays and 16 were selected for replicated study (Table 1). Three strains that were most suppressive to development of H. solani conidiophores (P8, P33, and P76) were selected for further study. Microbial strains P8 and P76 were significantly different than the $H$. solani-inoculated control $(P \leq 0.05)$. Conidiophores developed on 50 to $97 \%$ of the surface area of tubers in the replicated study.

Assays of soil microbial communities were divided into 3 groups of soil samples. The 3 most suppressive communities from each group were selected, although they were not significantly different than the controls $(P \leq 0.05)$. Two hundred strains were isolated from these 9 communities (101 from 7-day samples, 99 from 6-week samples), and 23 were selected for replicated study based on results of the single replication assays. Four strains ( $\mathrm{S} 28$, S244, S245, and S343) that were most effective in reducing conidia production of $H$. solani were selected for further study 44 to $97 \%$ of the surface area of the tubers in the replicated study.

Membrane plates. Three communities that were the most suppressive to conidial (Table 1). Conidiophores were present on

germination were selected from each of the assay groups ( 1 periderm and 3 soil) for a total of 12 communities. One hundred sixty-six strains were isolated and 27 were selected for replicated study based on results from the single replication assays. Six strains (PM1, PM27, PM40, SM11, SM13, and SM28) that were most effective in reducing conidial production by $H$. solani were selected for further study (Table 2). PM1 was the only strain that was significantly different than the $H$. solani-inoculated control $(P \leq 0.05)$ in replicated assays.

Efficacy of superior strains against additional strains of $\boldsymbol{H}$. solani. When the selected strains from both isolation methods were assayed against three strains of $H$. solani, none of the putative antagonists consistently reduced $H$. solani conidiophore production below the control levels (Table 3). PM1 and P76 significantly reduced disease in the first experiment against $H$. solani SS2-2 (34\% of the inoculated control), but not in later experiments.

Antagonist identification. Selected microbial strains that significantly inhibited $H$. solani $(P \leq 0.05)$ in at least one experiment were identified as Pseudomonas putida (PM1), Nocardia globerula (S244), and Xanthomonas campestris (P76) (Table 4). The 13 strains assayed against 3 strains of $H$. solani were deposited in the NRRL Culture Collection.

Tuber colonization by three strains. The rifampicin-resistant strains of PM1 and P76 (PM1r and P76r, respectively) were below detectable levels after 6 weeks on the surface of the potato tubers (Fig. 1). Yet, PM1r reduced the surface area affected by silver scurf in experiment 2 (Table 5). Increasing the concentration of

Table 2. Replicated assays of putative antagonists selected from the single replicate assays of membrane isolates

\begin{tabular}{|c|c|c|c|c|c|}
\hline Strain & $\begin{array}{l}\text { \% surface area } \\
\text { affected }^{\mathrm{a}}\end{array}$ & $\begin{array}{c}(\% \text { of } \\
\text { control })\end{array}$ & Strain & $\begin{array}{c}\text { \% surface area } \\
\text { affected }^{\mathrm{a}}\end{array}$ & $\begin{array}{c}(\% \text { of } \\
\text { control) }\end{array}$ \\
\hline PM 1 & $19 * *$ & (30) & SM218 & 64 & (108) \\
\hline PM 3 & 58 & (93) & SM233 & 77 & (129) \\
\hline PM 4 & 55 & (88) & SM234 & 94 & (158) \\
\hline PM27 & 27 & (42) & SM235 & 41 & (69) \\
\hline PM31 & 50 & (80) & SM242 & 77 & (129) \\
\hline PM36 & 42 & (67) & SM304 & 64 & (108) \\
\hline PM40 & $23 *$ & (38) & SM321 & 75 & (126) \\
\hline PM42 & 67 & (108) & SM322 & 66 & (111) \\
\hline PM43 & 30 & $(48)$ & SM323 & 42 & (71) \\
\hline SM6 & 57 & (90) & SM334 & 75 & (126) \\
\hline SM11 & 28 & (45) & $\mathrm{UC}^{\mathrm{b}}$ & 25 & $(42)$ \\
\hline SM13 & $25 *$ & $(40)$ & Control (+HS) & 59 & \\
\hline SM21 & 65 & (105) & & & \\
\hline SM25 & 31 & $(50)$ & & & \\
\hline SM28 & 27 & (42) & & & \\
\hline SM46 & 39 & (62) & & & \\
\hline SM47 & 50 & (80) & & & \\
\hline Control (+HS) & 63 & & & & \\
\hline $\mathrm{LSD}_{0.05}$ & 43.4 & & & 49.5 & \\
\hline
\end{tabular}

a Means represent the average of 4 replicates. Values within a column are significantly different from the inoculated control (+HS) at $P \leq 0.10\left(^{*}\right), P \leq 0.05(* *)$ or $P \leq 0.01$ (***) based on Fisher's protected least significant difference (LSD).

b Uninoculated control. 
PM1 10-fold did not increase disease control (Table 5). P8r, which colonized the tuber surface (Fig. 1), represented only $3 \%$ of the total bacterial population (Fig. 1) and did not control silver scurf. Fungal recovery generally increased from 200 $\mathrm{CFU} / \mathrm{cm}^{2}$ at 0 weeks to $9.04 \times 10^{4}$ $\mathrm{CFU} / \mathrm{cm}^{2}$ at 6 weeks.

\section{DISCUSSION}

A variety of techniques and strategies have been suggested for the isolation of microbial antagonists $(2,6,12,16,18)$. Transfer of microbiota to a common background soil assures that disease suppression exhibited by an experimental soil is biological in nature and not due to chemical, physical, or nutritional attributes of the soil. Using this technique, larger numbers of communities can be screened and individual isolates selected from only those communities exhibiting suppressiveness to plant disease.

Selection of suppressive microbial communities was an effective technique for reducing the number of soils utilized for isolating individual microbial strains. Periderm-enrichment may enhance natural suppressiveness in field soils, although its effect was not tested in this study. Two of the more suppressive strains from this study (S244 and S245) originated from soil that had been in continuous potato production for more than 25 years. Heat shocking dilution tubes may have favorably influenced the recovery of effective strains as $4 \%$ (5 of 115 tested) of heat shocked vs. $1 \%$ (1 of 135 tested) of non-heat-shocked strains were in the group of 13 selected strains.

Membrane plates speeded the selection process by 4 weeks, but did not yield the same microorganisms as the whole tuber assay. The membrane assay might be valuable for rapidly selecting antagonists that inhibit conidial germination, since the assay was conducted under nutrient and temperature conditions similar to those encountered in situ. However, biological control of silver scurf could also function via inhibition of mycelial growth, conidiophore formation, or periderm penetration, or by induced host resistance. Thus, whole tuber bioassay needs to be conducted so as not to exclude the selection of antagonists active by these alternative mechanisms.

Initial screens of the isolated microorganisms suggested that several strains were capable of controlling silver scurf. However, this study demonstrates the difficulty in obtaining biological control of silver scurf on a consistent basis. Several of the selected isolates reduced the disease level to that of the uninoculated control in some experiments, yet variability was so high that many strains that appear to substantially reduce disease were not significantly different from the inoculated controls.

Several factors were identified as possi- ble sources of variation in these experiments. Tubers may have been infected in the field, but did not show signs of disease when inoculated. The uninoculated controls show various levels of background disease (0 to $88 \%$ for individual tubers, data not shown). Inoculating with $H$. solani should have made the disease levels more uniform, but generally did not. The amount of variability in the uninoculated controls demonstrates the difficulty of selecting disease-free experimental material.

Jellis and Taylor (10) found that developing tubers were resistant to silver scurf until 10 weeks after tuber initiation. Merida et al. (15) found that early maturing cultivars were more susceptible to the disease. Tubers used in the present study were small and may not have been fully mature at harvest, which could have contributed to the high variability in tuber susceptibility to silver scurf seen in these experiments.

Jellis and Taylor (11) found that silver scurf multiplies during brief periods of free moisture in the storage area. Free moisture occurs when a temperature change causes

Table 4. Identification of 13 microbial strains selected for biological control of silver scurf of potato tubers

\begin{tabular}{lrc}
\hline Strain & Identification & NRRL accession \\
\hline P8 & Aureobacterium barkeri & B-21585 \\
P33 & Micrococcus kristinae & B-23008 \\
P76 & Xanthomonas campestris & B-21587 \\
S28 & Bacillus brevis & B-23009 \\
S244 & Nocardia globerula & B-21586 \\
S245 & Streptomyces sp. & Y-16990 \\
PM1 & Pseudomonas putida & B-21588 \\
PM27 & Trichosporon sp. & Y-17925 \\
PM40 & Arthrobacter ilicis & B-23010 \\
SM11 & Trichosporon sp. & Y-17926 \\
SM13 & Bacillus sphaericus & B-23011 \\
SM28 & Xanthomonas campestris & B-23012 \\
S343 & Clavibacter michiganensis & \\
\hline
\end{tabular}

Table 3. Effect of selected antagonistic strains on conidiophore development in Red Norland potato tubers of Helminthosporium solani strains SS2-2 (thiabendazole-sensitive), HSND07 (thiabendazole-resistant), and HSND25 (thiabendazole-sensitive)

\begin{tabular}{|c|c|c|c|c|c|c|}
\hline \multirow[b]{3}{*}{ Strain } & \multicolumn{6}{|c|}{ Surface area affected $(\%)$} \\
\hline & \multicolumn{2}{|c|}{ SS2-2 ${ }^{a}$} & \multicolumn{2}{|c|}{ HSND07 $^{b}$} & \multicolumn{2}{|c|}{ HSND25 $^{\mathrm{b}}$} \\
\hline & Experiment 1 & Experiment 2 & Experiment 1 & Experiment 2 & Experiment 1 & Experiment 2 \\
\hline$\overline{\mathrm{P} 8}$ & 21.2 & 21.2 & 23.5 & 12.5 & 42.6 & 38.8 \\
\hline P33 & 23.6 & 23.8 & 57.8 & 22.0 & 21.2 & 24.0 \\
\hline P76 & $11.2 * *$ & 26.4 & 45.5 & 64.0 & 28.8 & 34.8 \\
\hline $\mathrm{S} 28$ & 22.4 & 26.4 & 45.5 & 21.5 & 13.8 & 57.8 \\
\hline S244 & 16.4 & 40.0 & $3.0 * *$ & 20.5 & 38.8 & 32.4 \\
\hline S245 & 18.8 & 16.4 & 12.5 & 17.0 & 38.8 & 21.2 \\
\hline S343 & 33.8 & 16.2 & 37.5 & 25.0 & 1.2 & $7.4 *$ \\
\hline PM1 & $11.2 * *$ & 13.8 & 10.8 & 43.8 & 18.6 & 41.2 \\
\hline PM27 & 25.0 & 33.6 & 15.5 & 34.3 & 9.8 & 28.8 \\
\hline PM40 & 21.0 & 20.2 & 45.5 & 29.8 & 20.0 & 21.4 \\
\hline SM11 & 23.8 & 33.6 & 31.0 & 59.3 & 27.6 & 49.0 \\
\hline SM13 & 42.6 & 22.4 & 28.0 & $3.0 *$ & 15.0 & 26.4 \\
\hline SM28 & 40.0 & 23.8 & 22.0 & 58.0 & 32.6 & 21.2 \\
\hline Control (+HS) & 32.6 & 28.6 & 31.0 & 21.9 & 8.2 & 25.6 \\
\hline $\mathrm{UC}^{\mathrm{c}}$ & 10.0 & 13.8 & 37.5 & 40.8 & 26.2 & 28.8 \\
\hline
\end{tabular}

a Means represent the average of 5 replicates. Percentages were ranked within blocks. ANOVA and mean comparisons were performed on the ranked data. Values within a column are significantly different from the inoculated control (+HS) at $P \leq 0.10(*), P \leq 0.05(* *)$, or $P \leq 0.01(* * *)$ based on Fisher's protected least significant difference (LSD).

b Means represent the average of 4 replicates.

${ }^{\mathrm{c}}$ Uninoculated control. 
condensation of moisture from the air onto cold surfaces, such as potato tubers. In the early studies it was found that free moisture formed more readily in trays stored in certain positions within the incubators. This problem was partially corrected by rotating the trays biweekly to provide more uniform distribution of temperature changes. Yet, temperature changes un- doubtedly still contributed to the variability problems encountered.

The taxa of the selected strains are known to contain several plant pathogens. Whether they incite disease in their potential host species was not tested. Although Streptomyces sp. and Pseudomonas sp. are known to contain strains pathogenic to potato tubers, we did not see evidence of

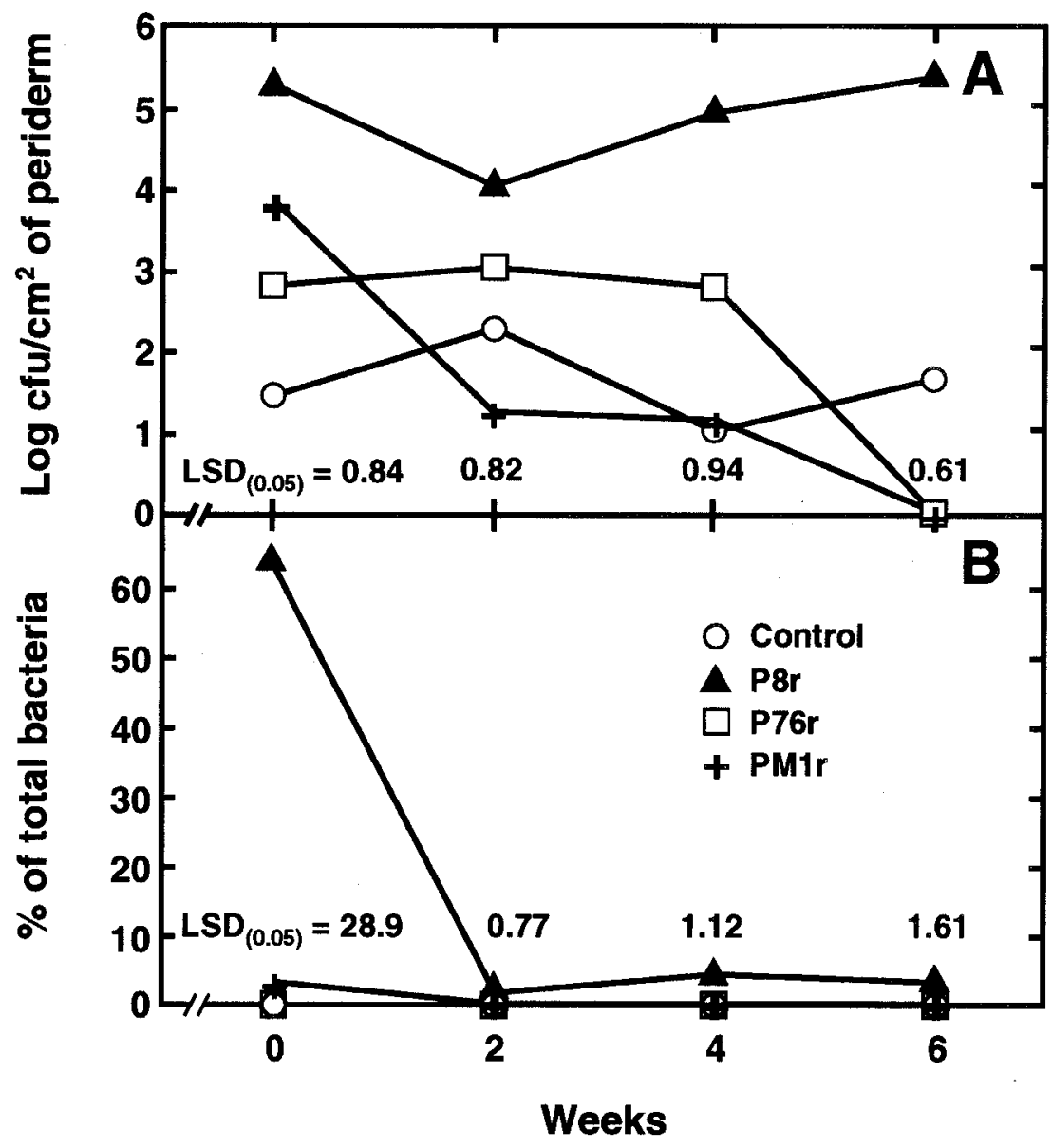

Fig. 1. (A) Colonization of Helminthosporium solani-inoculated Red Norland tubers by rifampicinresistant putative antagonists and (B) percentage of total bacteria isolated from tuber periderm that are rifampicin-resistant at $0,2,4$, and 6 weeks. Means represent the average of 2 experiments with 4 replicates each. Control $=H$. solani-inoculated control. $\mathrm{LSD}_{(0.05)}=$ Fisher's Protected LSD at $P \leq$ 0.05 .

Table 5. Effect of wild-type and rifampicin-resistant microbial strains on conidiophore development by Helminthosporium solani SS2-2 on Red Norland potato tubers

\begin{tabular}{|c|c|c|c|c|}
\hline \multirow[b]{3}{*}{ Treatment } & \multicolumn{4}{|c|}{ Surface area affected $(\%)^{\mathrm{a}}$} \\
\hline & \multicolumn{2}{|c|}{ Experiment 1} & \multicolumn{2}{|c|}{ Experiment 2} \\
\hline & Wild & Rif & Wild & Rif \\
\hline P8 & 77 & 63 & 53 & 72 \\
\hline P76 & 51 & 81 & 66 & 59 \\
\hline PM1 & 61 & 55 & 73 & $47 * *$ \\
\hline $\operatorname{PM} 1(10 x)^{b}$ & 64 & & 53 & \\
\hline Control (+HS) & 64 & & 75 & \\
\hline $\mathrm{UC}^{\mathrm{c}}$ & 75 & & 78 & \\
\hline $\mathrm{LSD}_{0.05}$ & 20.8 & & 23.5 & \\
\hline
\end{tabular}

a Means represent the average of 4 replicates. Values within a column are significantly different from the inoculated control (+HS) at $P \leq 0.10(*), P \leq 0.05(* *)$ or $P \leq 0.01(* * *)$ based on Fisher's protected least significant difference (LSD).

b $10 \times$ concentration of PM1 $\left(\mathrm{OD}=1.7\right.$ at $\left.A_{620}\right)$.

${ }^{\mathrm{c}}$ Uninoculated control. pathogenicity from any of the biological control strains assayed on tubers of cultivars Red Norland or Russet Burbank (unpublished results).

Many of the possible mechanisms of biological control would require an antagonist to be a good periderm colonist. In this study, PM1 showed some control of $H$. solani without colonizing the tuber surface, indicating that cellular metabolites likely inhibited the growth of silver scurf. These metabolites were not identified in this study. On the other hand, P8r, which was somewhat successful as a periderm colonist, did not control silver scurf.

This was the first attempt at large-scale screening for biological control agents active against silver scurf of potato tubers. Continued research is warranted, because resistance of $H$. solani to thiabendazole is widespread and other postharvest chemical controls are limited. Our results indicate that in at least some instances, long-term colonization of the tuber surface may not be necessary to reduce disease. However, studies to determine whether biocontrol activity can be increased or extended via the use of antagonist-specific nutrient amendments could also be useful. Determining the mode of action of selected strains should help explain why biological control activity can be so variable and how to improve utilization of the antagonist.

\section{ACKNOWLEDGMENTS}

We thank the many researchers who supplied potato tubers and soil samples for this study, R. Loria for supplying the strains of $H$. solani, and C. Kurtzman, D. Labeda, and H. Wyckoff for assistance with identification of the microorganisms. Phospholipid fatty acid analysis was conducted by L. Nakamura. Names are necessary to report factually on available data; however, the USDA neither guarantees nor warrants the standard of the product, and the use of the name by USDA implies no approval of the product to the exclusion of others that may also be suitable.

\section{LITERATURE CITED}

1. Adams, A., Sandar, N., and Nelson, D. C. 1970. Some properties of soils affecting russet scab and silver scurf of potatoes. Am. Potato J. 47:49-57.

2. Andrews, J. H. 1985. Strategies for selection antagonistic microorganisms from the phylloplane. Pages 31-44 in: Biological Control on the Phylloplane. C. E. Windels and S. E. Lindow, eds. American Phytopathological Society, St. Paul, MN.

3. Burke, O. D. 1938. The silver-scurf disease of potatoes. Cornell Univ. Agric. Exp. Stn. Bull. 692.

4. Chalutz, E., and Droby, S. Biological control of postharvest diseases. in: Plant-Microbe Interaction and Biological Control. G. J. Boland and L. D. Kuykendall, eds. Marcel Dekker, Inc., New York. In press.

5. Chun, W. W. C., and Shetty, K. K. 1994. Control of silver scurf disease of potatoes caused by Helminthosporium solani Dur. \& Mont. with Pseudomonas corrugata. Phytopathology 84:1090.

6. Cook, R. J. and Baker, K. F. 1983. The Nature and Practice of Biological Control of Plant Pathogens. American Phytopathological Society, St. Paul, MN

7. Fravel, D. R. and Larkin, R. P. 1996. Avail- 
ability and application of biocontrol products. Biological and Cultural Tests 11:1-7.

8. Hide, G. A., Hall, S. M., and Boorer, K. J. 1988. Resistance to thiabendazole in isolates of Helminthosporium solani, the cause of silver scurf disease of potatoes. Plant Pathol. 37:377-380.

9. Janisiewicz, W. J. Biological control of postharvest diseases of temperate fruits: challenges and opportunities. in: Plant-Microbe Interaction and Biological Control. G. J. Boland and L. D. Kuykendall, eds. Marcel Dekker, Inc., New York. In press.

10. Jellis, G. J. and Taylor G. S. 1977a. Control of silver scurf (Helminthosporium solani) disease of potato with benomyl and thiabendazole. Ann. Appl. Biol. 86:59-67.

11. Jellis, G. J. and Taylor G. S. 1977b. The development of silver scurf (Helminthosporium solani) disease of potato. Ann. Appl. Biol. 86:19-28.

12. Kloepper, J. W. 1991. Development of in vivo assays for selecting potential rhizobacterial biological control agents against Rhizoctonia solani on cotton. Pages 238-242 in: Plant Growth-Promoting Rhizobacteria Progress and Prospects. Int. Workshop Plant Growth-Pro- moting Rhizobacteria 2nd. WPRS Bull. 14.

13. Krieg, N. R., ed. 1984. Bergey's Manual of Systematic Bacteriology. Vol. I. Williams \& Wilkins, Baltimore.

14. Merida, C. L. and Loria, R. 1994. Comparison of Thiabendazole-sensitive and -resistant Helminthosporium solani isolates from New York. Plant Dis. 78:187-192.

15. Merida, C. L., Loria, R., and Halseth, D. E. 1994. Effects of potato cultivar and time of harvest on the severity of silver scurf. Plant Dis. 78:146-149.

16. Merriman, P., and Russell, K. 1990. Screening strategies for biological control. Pages 427435 in: Biological Control of Soil-borne Plant Pathogens. D. Hornby, ed. C.A.B. International, Oxon, England.

17. Nolte, P., Shetty, K., and Patterson, P. 1994. Understanding and controlling silver scurf of potato. The Badger Common'tater, Jan. 1994 pp. 5-12.

18. Schisler, D. A., Ryder, M. H., and Rovira, A. D. 1991. An improved in vitro technique for rapidly assaying rhizosphere bacteria for the production of compounds inhibitory to Rhizoctonia solani and Gaeumannomyces graminis var. tritici. Pages 302-303 in
Beltsville Symp. in Agric. Res. Vol. 14. The Rhizosphere and Plant Growth. D. L. Keister and P. B. Cregan, eds. Kluwer Academic Publishers, Boston.

19. Schisler, D. A. and Slininger, P. J. 1994. Selection and performance of bacterial strains for biologically controlling Fusarium dry ro of potatoes incited by Gibberella pulicaris Plant Dis. 78:251-255.

20. Secor, G. A., and Gudmestad, N. C. 1994 Post-harvest diseases-dry rot, silver scurf Valley Potato Grower (7):16-18.

21. Secor, G. A., Rodriguez, D., Rodriguez, J., and Gudmestad, N. C. 1994. Distribution and incidence of benzimidazole-resistant Fusarium sambucinum and Helminthosporium solani isolated from potato in North America. BCPC Monograph 60:271-274.

22. Sugimoto, E. E., Hoitink, H. A. J., and Tuovinen, O. H. 1990. Enumeration of oligotrophic rhizosphere pseudomonads with diluted and selective media formulations. Biol. Fertil. Soils 9:226-230.

23. Wisniewski, M. E., and Wilson, C. L. 1992 Biological control of postharvest diseases of fruits and vegetables: Recent advances. HortScience 27:94-98. 